\title{
RELAÇÕES TERRITORIAIS ENTRE POVOS INDÍGENAS E AGRONEGÓCIO NO BRASIL: CONFLITOS E RESISTENNCIAS
}

\author{
TERRITORIAL RELATIONS BETWEEN INDIGENOUS PEOPLES AND AGRIBUSINESS IN \\ BRAZIL: CONFLICTS AND RESISTANCE
}

\author{
${ }^{\text {A }}$ Universidade Federal Rural do Rio de Janeiro (UFRRJ), Seropédica, RJ, Brasil \\ ${ }^{\text {B }}$ Doutoranda na Universidade Federal do Rio de Janeiro (UFRJ), Rio de Janeiro, RJ, Brasil \\ ${ }^{\mathrm{C}}$ Doutoranda na Universidade do Estado do Rio de Janeiro (UERJ), Rio de Janeiro, RJ, Brasil
}

Recebido em: 02/12/2021 |04/01/2022 DOI: $10.12957 /$ tamoios.2022.63879

Correspondência para: Roberta Carvalho Arruzzo (betarruzzo@hotmail.com)

\begin{abstract}
Resumo
O presente artigo objetiva analisar as relações territoriais que se estabelecem entre os povos indígenas e o agronegócio no Brasil. Para isso, dialogamos com alguns pensadores que contribuem para a abordagem territorial, sendo eles, essencialmente: Sack (1986), Raffestin (1993) e Santos (1996; 1999). Partimos da construção da noção de relações territoriais para analisarmos as principais relações territoriais conflituosas entre agronegócio e Povo Indígenas no Brasil. Estas relações são analisadas a partir de cinco categorias: jurídico-legislativa, ambiental, invasões territoriais e violências físicas. Por fim, enfocamos as relações territoriais que se estabelecem entre os setores do agronegócio e os Guarani e Kaiowá no Mato Grosso do Sul, entendendo-o como um caso representativo no que se refere às relações sobre as quais este artigo se debruça.
\end{abstract}

Palavras-chave: Relações Territoriais; Povos Indígenas; Agronegócio; Brasil

\begin{abstract}
This article aims to analyze the territorial relations established between indigenous peoples and agribusiness in Brazil. For this, we dialogued with some thinkers who contribute to the territorial approach, namely: Sack (1986), Raffestin (1993) and Santos $(1996 ; 1999)$. We start from the construction of the notion of territorial relations to analyze the main conflicting territorial relations between agribusiness and Indigenous People in Brazil. These relationships are analyzed from five categories: legal-legislative, environmental, territorial invasions and physical violence. Finally, we focus on the territorial relationships that are established between the agribusiness sectors and the Guarani and Kaiowá in Mato Grosso do Sul, understanding it as a representative case in terms of the relationships that this article focuses on.
\end{abstract}

Keywords: Territorial Relations; Indigenous people; Agrobusiness; Brazil 


\section{INTRODUÇÃO}

O Brasil é um país de grande diversidade sociocultural e étnica, que resulta em enorme heterogeneidade social, econômica e cultural. Esta diversidade e tudo que ela representa em termos de diferentes espacialidades e territorialidades, embora bastante presente em todas as regiões brasileiras, é ainda pouco entendida como componente de centralidade nos estudos geográficos. Milton Santos (1996), ao nos propor uma epistemologia das existências, chamava a atenção para a necessidade de levarmos em consideração esta diversidade de presenças no espaço com muito cuidado, sendo todas relevantes para os geógrafos, independentemente de sua dimensão numérica ou econômica, por exemplo.

A expansão da agricultura moderna no Brasil vem acompanhada de um forte componente de negação desta diversidade, tanto no que se refere à tendência de homogeneização das práticas produtivas, à redução das espécies cultivadas, quanto à negação das diferentes sociedades, culturas e territorialidades. Neste sentido, nossas leituras sobre o agronegócio têm sido construídas buscando entender os efeitos de sua expansão a partir das relações que constituem parte desta enorme diversidade, focando nas relações territoriais que se estabelecem entre as diferentes atividades produtivas relacionadas ao agronegócio e às monoculturas empresariais e os povos indígenas no Brasil.

Neste contexto, estamos desenvolvendo, desde 2011, uma série de projetos relacionados à situação territorial dos Guarani e Kaiowá e às atividades produtivas (especialmente agrícolas - os chamados "fazendeiros") em Mato Grosso do Sul. Os resultados de nossas pesquisas têm apontado para importantes diferenças entre a espacialidade e regionalização de atividades relacionadas aos diferentes setores do que comumente chamamos de agronegócio e às formas como as diferentes atividades se relacionam territorialmente com os povos indígenas. No presente texto apontaremos algumas análises que realizamos a partir das tipologias dos conflitos e das relações territoriais que viemos desenvolvendo, em especial no que se refere aos setores sucroenergético e carne grãos e os Guarani e Kaiowá no Mato Grosso do Sul.

Num primeiro momento, explicamos brevemente o que pensamos teoricamente por relações territoriais e como temos embasado nossas pesquisas. $\mathrm{Na}$ segunda parte do texto, apresentamos algumas sistematizações de uma proposta de categorização inicial dos tipos de conflitos territoriais envolvendo os povos indígenas e agronegócio no Brasil. Por fim, apontamos alguns aspectos sobre as diferentes formas de atuação dos ramos produtivos do agronegócio e as relações que estabelecem com os Guarani e Kaiowá. 


\section{GEOGRAFIA: OPACIDADES, EXISTÊNCIAS E AS RELAÇÕES TERRITORIAIS}

Em outros momentos, já abordamos com mais detalhe os elementos teóricos que compõem o que chamamos de relações territoriais (Arruzzo, 2009 e 2013). Faremos aqui apenas alguns apontamentos do que consideramos fundamental em nossa proposta de diálogo entre diferentes autores. Um primeiro ponto, central em nossas concepções, é a já apontada diversidade sociocultural e, consequentemente, territorial brasileira. Consideramos fundamental contribuirmos para a visibilização de sujeitos (e seus territórios e territorialidades) muitas vezes desconsiderados em práticas e discursos espaciais. Como nos indica Souza Santos, esta invisibilidade de certos sujeitos e suas práticas espaciais é ativamente produzida:

São, assim, cinco as principais formas sociais de não-existência produzidas ou legitimadas pela razão metonímica: o ignorante, o residual, o inferior, o local, o improdutivo. Trata-se de formas sociais de inexistência porque as realidades que elas conformam estão apenas presentes como obstáculos em relação às realidades científicas, avançadas, superiores, globais ou produtivas. (Souza Santos, 2006, p. 789).

Santos (1996), através da perspectiva do espaço banal, nos chamava a atenção para a multiplicidade de existências e suas implicações epistemológicas. Categorias como espaços opacos, homens lentos, território usado (Santos, 1999) são importantes apoios conceituais para tentarmos dar conta destas presenças e existências. Nosso caminho tem sido através do diálogo destas premissas epistemológicas com os conceitos de territorialidade e território, em suas perspectivas relacionais.

Buscamos atentar não apenas para a materialidade do território, seus limites ou mesmo seu aspecto mais econômico, mas sim pelas ações realizadas pelos diferentes sujeitos e agentes para que o território exista e seja mantido, quem as realizou, para quê e de que forma. Entendemos o território como uma área apropriada por agentes sociais e que é organizado, vivido, estruturado com base em três elementos fundamentais: nós, redes e malhas ou tessituras (Raffestin, 1993). Como nenhum agente social está sozinho, como há uma constante relação com outros agentes e seus territórios, o que em geral é percebido pelo geógrafo é o sistema territorial, são os territórios dos diferentes atores em relações uns com os outros (Idem).

Neste sentido, a proposta conceitual de Robert Sack (1986) nos parece oferecer uma direção possível para o diálogo. Para este autor, a territorialidade é uma estratégia geográfica que consiste na "tentativa, por indivíduo ou grupo, de afetar, influenciar, ou controlar pessoas, fenômenos e relações, ao delimitar seu controle sobre uma certa área geográfica” (Sack, 2011, p. 76). Sendo assim, esta estratégia pode ser empregada ou não, dependendo das vantagens que ofereça ao sujeito da ação já que "por fazê-la uma estratégia coloca-se a territorialidade inteiramente dentro do contexto de motivações e objetivos" (Sack, 2011, p. 79). Assim entendida, as territorialidades podem ser empregadas com sentidos, significados, absolutamente distintos, segundo os sujeitos da ação e seu momento histórico. Pensamos ser 
fundamental, enfim, compreendermos os sentidos das ações (Ribeiro, 2001) envolvidas nos conflitos territoriais.

Este foco nas ações envolvidas nas territorialidades e territórios nos conduz a entendermos o sistema territorial (Raffestin, 1993) através deste foco nas relações entre os agentes (ou sujeitos, em alguns casos), em como estas relações envolvem dissimetrias de poder e, também, resistências e insurgências. Este esforço em direção à compreensão dos sentidos da ação territorial nos remete aos movimentos metodológicos de diálogo, escuta e, em muitos casos, tradução (Souza Santos, 2006). Este caminho metodológico se apoia num diálogo horizontal entre conceitos e noções acadêmicos e os conceitos e noções dos povos com quem dialogamos.

Em nossas pesquisas sobre as relações territoriais entre agronegócio e os Guarani e Kaiowá, uma palavra que ganha destaque é tekoha, que envolve as ideias de modo de vida e lugar, podendo ser entendido como o lugar onde se pode viver do seu modo. Este termo, embora possa parecer simples à primeira vista, tem diversas dimensões, incluindo os seres invisíveis com os quais os Kaiowá devem manter uma complexa relação respeitosa para que possam plantar, caçar ou coletar frutos e vegetais. Tonico Benites, destacado antropólogo kaiowá, afirma que:

\footnotetext{
Em relação ao significado vital do território para o povo guarani-kaiowá, é preciso observar em detalhe $o$ relacionamento desses indígenas com seres invisíveis/guardiões (protetores/deuses) da terra, manifestado através de cantos e rituais diversos dos líderes espirituais. A forma de diálogo e respeito com estes seres humanos invisíveis marca uma diferença muito importante em relação à percepção e ao uso dos recursos naturais da terra (2012, p. 2).
}

Eliel Benites, outro importante acadêmico Kaiowá, também nos ajuda a compreender parte da densidade dos conceitos espaciais de seu povo:

\begin{abstract}
Podemos então afirmar que o espaço geográfico na visão guarani kaiowá é o tekoha, devido à sua produção a partir das relações, com múltiplos elementos que o compõem em suas dimensões sociais e sobrenaturais. O que leva a produzir o tekoha é a busca por obter relações permanentes com as divindades e, para isso, o teko (modo de ser), deve ser vivido de acordo com as regras tradicionais. Assim, o objetivo do preparo ou da educação do sujeito é a demanda por esta relação; nesta busca permanente, se constrói uma trajetória específica, que marca, produzindo o tekoha. (2020, p. 25)
\end{abstract}

Tekoha, nesse sentido, é um caminho por onde o sujeito caminhou e ainda caminha, no tempo e no espaço, dando sentido à existência. Estas diferentes dimensões e densidades nos indicam algumas direções para compreendermos os sentidos da ação territorial envolvidos no movimento político que vem sendo realizado pelos Guarani e Kaiowá para recuperar os tekoha (Benites, 2014). Território e tekoha não são sinônimos, mas são ideias que dialogam e que acionamos para entendermos o que aqui nomeamos de relações territoriais.

\title{
RELAÇÕES TERRITORIAIS ENTRE INDÍGENAS E AGRONEGÓCIO NO BRASIL
}


Desde os anos 1970 as monoculturas empresariais têm crescido em produção e áreas ocupadas no Brasil. Este crescimento, fortemente associado à expansão da agricultura moderna para as áreas de cerrados, vem aumentando a quantidade produzida e exportada de grãos (em especial a soja) e carnes. Esta expansão vem acompanhada de aumento da concentração fundiária e econômica e pela crescente importância do capital financeiro nas atividades agrícolas. Estes processos de expansão, por outro lado, assumem contornos mais intensos a partir dos anos 2000, com um fortalecimento das apropriações de territórios e recursos naturais, com forte apoio do Estado (Leite, 2018).

Esta expansão do agronegócio no Brasil apresenta importantes modificações de ordem técnica, política, financeira e produtiva, que se manifestam espacialmente através de um movimento articulado de expansão e concentração (Frederico, 2015). Denise Elias nos aponta as profundas repercussões destes processos na (re)organização do território brasileiro, em parte devido à formação de regiões agrícolas especializadas (Elias, 2011). Em muitos casos, o estabelecimento de regiões produtivas modernas vem acompanhado de um forte discurso desenvolvimentista e de estratégias de invisibilização de toda uma história das pessoas e de seu espaço vivido, tratando estes espaços como "vazios" ou como anteriormente improdutivos (Porto-Gonçalves, 2008).

Diversas sociedades e seus territórios são entendidos, tanto por agentes privados como pelo planejamento estatal, como residuais, improdutivas ou inexistentes, levando a relações territoriais bastante dissimétricas em termos de poder e recursos. Esta dissimetria tem resultado em diversas formas e aspectos de conflitos territoriais. Neste momento, nos interessam as relações territoriais conflituosas que o agronegócio estabelece com os povos indígenas brasileiros e com as Terras Indígenas, buscando acessar recursos, impedir sua criação (regularização) ou mesmo a manutenção das já existentes.

A partir de nossas pesquisas sobre as relações territoriais entre os diferentes setores produtivos do agronegócio e os Guarani e Kaiowá, temos estabelecido uma pequena tipologia dos conflitos territoriais e das formas como os agentes vinculados ao agronegócio costumam interferir diretamente nas questões territoriais dos povos indígenas. Abordaremos, com base em nossas pesquisas, documentos e dados produzidos por diferentes órgãos ligados à questão indígena, alguns apontamentos sobres estas formas de ação no que diz respeito aos seguintes tipos de conflitos: jurídico-legislativo; invasões territoriais; ambientais; e violências físicas. Importante destacarmos que esta proposta de tipologia dos conflitos territoriais não implica em categorias que se excluem. Em realidade, uma mesma ação pode ser enquadrada em mais de um tipo. Buscamos aqui apenas sistematizar alguns dos tipos de ação do agronegócio que têm interferido diretamente nas questões territoriais indígenas do Brasil.

Um primeiro tipo de relação territorial que aponta para conflitos é o que estamos nomeando de jurídico-legislativo. As Terras Indígenas, que são coletivas e de usufruto exclusivo dos povos indígenas, são categorias jurídicas baseadas atualmente na Constituição Nacional, promulgada em 1988, que veio a romper, ao menos em teoria, com toda uma 
tradição legal em se tratar os povos indígenas como um elemento do passado. Grande parte dos entendimentos legais brasileiros sobre a questão indígena, anteriormente os considerava como grupos que ainda sobreviviam e deveriam ser protegidos, mas estariam fadados a se mesclar com a sociedade "civilizada" e, portanto, perder seus direitos legais às terras por eles ocupadas.

A partir de 1988 os povos indígenas, seus direitos à terra e à manutenção de seu modo de vida e sua cultura, deixam de ser vistos como transitórios. A regularização de Terras Indígenas é um processo administrativo, que tem se tornado cada vez mais lento e que envolve diversas fases: identificação, delimitação, demarcação, homologação e finalmente regularização. Somado a isso, a finalização deste processo e completa regulação fundiária por si só não garante, em muitos casos, que os povos indígenas possam realmente usufruir de seus direitos territoriais.

Neste sentido, um dos principais campos de atuação do agronegócio no Brasil que, como vimos, cresce consideravelmente nos anos posteriores à Constituição de 1988, tem sido atuar legal e juridicamente atrasando, embargando, interferindo ou tentando modificar o processo de regularização das Terras Indígenas no Brasil. Esta atuação se dá em diversas instâncias e de formas diferentes. Apontaremos aqui alguns de seus aspectos.

Um primeiro ponto se refere à atuação legislativa dos parlamentares brasileiros, em grande parte vinculados à Bancada Ruralista ou à Frente Parlamentar Agropecuária que, no que concerne às Terras Indígenas, têm apoiado uma série de tentativas de modificação dos direitos garantidos pela Constituição de 1988, através de uma série de projetos de lei (PL) ou projetos de emenda constitucional (PEC). Alceu Castilho (2012) nos demonstra em dados, como muitos parlamentares brasileiros são também donos de terras, e isso se vincula a uma série de ações políticas. A Articulação dos Povos Indígenas do Brasil (APIB) tem realizado ações, através dos parlamentares indígenas e da denúncia e exposição das principais tentativas a cada período, no sentido de resistir a essas tentativas. Um dos últimos dossiês da APIB busca apontar as principais medidas legislativas em tramitação, todas envolvendo aspectos territoriais:

“1. PL 490/2007: propõe a transferência para o Congresso Nacional da competência de demarcar terras indígenas, entre outras medidas que violam os direitos de usufruto exclusivo das terras indígenas. Esta inovação, que desrespeita a Constituição, inviabiliza a demarcação de terras indígenas, possibilita ao governo retomar áreas reservadas aos indígenas, limita o usufruto e a gestão das terras por parte dos indígenas ao abrir o aproveitamento de recursos hídricos e potenciais energéticos para agentes externos. Finalmente, o projeto de lei viola o direito de consulta aos povos indígenas sobre a instalação de projetos e infraestruturas em seus territórios, e flexibiliza e desrespeita a política indigenista do não-contato com os povos indígenas isolados.

2. PL 2633/2020: conhecido como o PL da Grilagem, enfraquece os controles sobre a ocupação de terras públicas, abrindo caminho para anistiar grileiros e criminosos ambientais, em especial na Amazônia, assim como favorece a impunidade de crimes ambientais e promove dinâmicas de desmatamento e queimadas, ao passo que enfraquece as regras de regularização ambiental. $\mathrm{O}$ projeto foi aprovado sorrateiramente pela Câmara dos Deputados na noite do dia 03 de agosto, e agora segue para avaliação do Senado Federal. 
3. PL 984/2019: pretende cortar o Parque Nacional do Iguaçu, a última grande reserva da Mata Atlântica do interior do país, ao reabrir uma rodovia através do trecho mais ecologicamente sensível da área, habitada por espécies ameaçadas de extinção, como a onça pintada. A iniciativa vai promover o desmatamento e gerar graves impactos ecológicos, econômicos e no turismo na região. Estudos ambientais comprovam que a reabertura da rodovia trará o aumento da caça e do atropelamento de animais silvestres, o desmatamento, além de entrada de espécies exóticas invasoras, focos de queimada e poluição.

4. PROJETO DE DECRETO LEGISLATIVO 177/2021: autoriza o Presidente da República a denunciar a Convenção 169 da Organização Internacional do Trabalho (OIT), um dos principais instrumentos globais de proteção aos direitos dos povos originários e tradicionais.

5. PL 191/2020: autoriza a exploração das terras indígenas por grandes projetos de infraestrutura e mineração, abrindo espaço para realização de pesquisa e de lavra de recursos minerais e de hidrocarbonetos, para o aproveitamento de recursos hídricos visando à geração de energia elétrica em terras indígenas e institui a indenização pela restrição do usufruto de terras indígenas." (APIB, 2021)

Ainda podemos apontar mais uma ação dos parlamentares no que se refere diretamente às questões territoriais indígenas, via Comissões Parlamentares de Inquérito (CPI). Destacamos aqui duas CPI's: a CPI do INCRA e da FUNAI, instituída em 2016, para investigar a ação dos órgãos na demarcação de terras indígenas, e a CPI do CIMI no Mato Grosso do Sul, instituída em 2015. A forma de atuação dos parlamentares durantes estas CPIs e o teor dos relatórios finais demonstram seu forte cunho anti-indigenista.

Outro aspecto desta atuação jurídica-legislativa do agronegócio com relação aos povos indígenas brasileiros tem sido a judicialização dos processos de regularização fundiária das Terras Indígenas, que consiste no embargo de uma série de processos via ações judiciais. Sobre isso, a APIB tem realizado levantamentos para entender estes processos:

“(...) a DONR criou uma base de dados com 797 casos judicializados envolvendo: contestação sobre demarcação, desapropriação direta e indireta, interdição, reintegração/ manutenção de posse, revogação de licença ambiental, indenização por danos ambientais ou danos morais, entre outras categorias." (APIB, 2020b, p.12)

Somado a estas formas de atuação temos ainda a defesa de teses, como a do Marco Temporal (Amado, 2020), que podem embasar a contestação de diversas Terras Indígenas já regularizadas, além de impedir o reconhecimento de outras tantas. Os dados apresentados no Relatório do Conselho Indigenista Missionário (CIMI) dão a dimensão da quantidade de Terras Indígenas com o processo de regularização atrasado. No que se refere à omissão e morosidade do Estado no processo de regularização das terras, os dados do CIMI (2019) apontam que, num total de 1298 Terras Indígenas no país, 829 destas Terras estavam com pendências administrativas, sendo: 536 sem providências, 162 a identificar, 48 identificadas, 63 declaradas, 14 homologadas, 6 com portarias de restrição. Estes são apenas alguns aspectos desta forma de atuação jurídico-legislativa do agronegócio no que se refere às questões territoriais indígenas, em que, como nos indicou em entrevista uma liderança Kaiowá em encontro em 2018, "eles atacam na caneta".

Um segundo tipo de atuação do agronegócio junto aos povos e Terras Indígenas tem sido as invasões territoriais. Segundo dados do CIMI, entre janeiro e setembro de 2019, foram registradas 160 invasões de territórios indígenas, contra 109 em 2018, e 96 em 2017 (CIMI, 2019), o que evidencia um aumento crescente destas invasões. Ainda, segundo dados do CIMI, em 2019 foram registrados 256 casos de "invasões possessórias, exploração ilegal de 
recursos e danos ao patrimônio" em pelo menos 151 terras indígenas, de 143 povos, em 23 estados, o que representa um aumento de $134,9 \%$ dos casos registrados quando comparados ao ano anterior. Dentre os principais agentes que praticam estas ações (madeireiros, grileiros e fazendeiros), destacamos aqui os fazendeiros como uma parcela significativa destes dados.

Dados do Sistema de Gestão de Terras (SIGEF/INCRA) informam que até maio de 2020 foram certificadas 114 fazendas sobrepostas a áreas indígenas ainda não homologadas, o que contraria pareceres jurídicos prévios. Estas 114 fazendas representam um total 250 mil hectares de áreas indígenas. Parte destas terras são destinadas ao cultivo de commodities e à judicialização dos processos de regularização das Terras Indígenas que, como vimos, contribui para a lentificação do processo, fazendo com que estas fazendas permaneçam produzindo durante muito tempo, mesmo estando em área indígena. Além das invasões territoriais diretas, há também formas de invasões territoriais praticadas por agentes do agronegócio que se dão de maneira indireta, seja por projetos de logística de asfaltamento de estradas que cruzam as Terras Indígenas para fins de escoamento da produção, seja por arrendamento ilegal de Terras Indígenas para o cultivo de commodities, seja pela extração ilegal de recursos naturais.

A extração dos recursos naturais nos conduz ao nosso terceiro tipo de relações territoriais: os conflitos ambientais. As atividades produtivas vinculadas ao agronegócio têm, devido à própria forma como se organizam as atividades produtivas, enormes impactos ambientais (Altieri e Nicholls, 2020). Parte destes impactos atingem diretamente os povos indígenas e de várias formas, como queimadas, desmatamento e as poluição por agrotóxicos. Segundo dados produzidos, registrados no dossiê Saúde do Campo e Agrotóxicos:

\begin{abstract}
Entre os anos de 2007 e 2013, o volume de agrotóxicos utilizado no país aumentou de 643.057.017 kg para 1.224.997.637 kg. Paralelamente, o número de casos de intoxicação registrados no país também cresceu exponencialmente nos últimos anos. Segundo dados disponíveis no Sistema Nacional de Agravos de Notificação (Sinan), no período de 2007 a 2017 foram notificados 107.535 casos de intoxicação por agrotóxicos no Brasil. Desses 39.698 registros corresponderam a intoxicações por agrotóxico de uso agrícola, que responderam por $52,8 \%$ do total de óbitos relacionados a intoxicação por agrotóxicos no país, revelando que o uso de agrotóxicos representa um grave problema de saúde pública.(Gurgel; Santos; Gurgel, 2019, p. 24)
\end{abstract}

Os problemas que emergem das derivas de agrotóxico, por exemplo, se distribuem de modo desigual nos territórios, de modo que aqueles que habitam mais próximo às plantações - como estão muitas Terras Indígenas - acabam por ficar mais sujeitos à intoxicação. Dessa forma, a deriva atinge não apenas a saúde e integridade dos trabalhadores, como também das comunidades que vivem no entorno destas fazendas, seja via contaminação dos córregos e lençóis freáticos que alimentam as Terras Indígenas, seja via contaminação do ar, ocasionando uma série de problemas à saúde e dificuldade no cultivo de hortas orgânicas.

No que se refere aos incêndios criminosos, um levantamento realizado pela APIB afirma que mais de 200 povos indígenas foram diretamente impactados pelos incêndios em 2020, estando a maioria desses povos situados na Amazônia. Em termos de distribuição destes impactos entre as Unidades da Federação, o relatório divulgado pela APIB (2021) afirma que, "Mato Grosso, Pará e Tocantins possuem os piores índices de incêndios e estão entre as áreas com maior número de desmatamentos, uma influência direta do afrouxamento das políticas ambientais e do avanço agressivo do agronegócio nesses estados" (APIB, 2020, 
p.37). Em 2020, os incêndios florestais apresentaram os maiores índices nos últimos anos, impactando fortemente o Pantanal, a Amazônia e o Cerrado, e os povos e comunidades que aí residem. Em um contexto de pandemia de COVID-19, vírus este correlacionado a problemas respiratórios, as queimadas passam a representar uma dimensão ainda mais catastrófica no que se refere aos impactos sobre a saúde destes povos.

Destacamos aqui três dos biomas brasileiros mais ameaçados pelos impactos ambientais promovidos por agentes ligados ao agronegócio: Amazônia, Cerrado e Pantanal. O desmatamento e os incêndios criminosos na Amazônia são realizados para converter estas áreas de floresta primária em áreas agrícolas e, segundo levantamento feito pelo APIB, "um dos principais motores do desmatamento na Amazônia é o roubo de terras em áreas protegidas, como Terras Indígenas (TI) e Unidades de Conservação, para especulação" (APIB, 2020, p.5). Dados produzidos pela FAO sugerem a correlação direta entre a preservação das florestas nativas da América Latina e o papel dos povos indígenas.

A biodiversidade presente no Cerrado brasileiro também tem sido fortemente impactada pelo desmatamento, por incêndios criminosos e por derivas de agrotóxico, sobretudo para abrir áreas para a pecuária de gado de corte e para o cultivo de commodities. Segundo dados do IBGE, o Brasil já perdeu 50\% da flora original do Cerrado, e vem perdendo em ritmo cada vez mais acelerado. No que se refere ao Pantanal, o ano de 2020 foi emblemático com relação aos incêndios criminosos. Segundo dados levantados pelo INPE, foi a pior destruição em 23 anos, com mais de 16 mil focos de incêndio, o que vem gerando sérias consequências para os povos indígenas localizados na região. Dados levantados pelo ISA, registram que entre julho e agosto de 2020 foram 3.553 focos de calor em 148 Terras Indígenas.

Por fim, apontamos os aspectos destes conflitos que se referem às violências físicas, dentre as diversas as formas de violência praticadas contra os povos indígenas por parte dos agentes que compõem o agronegócio. Segundo dossiê produzido pela Anistia Internacional,

\begin{abstract}
As Américas continuaram sendo uma das regiões mais perigosas do mundo para defender os direitos humanos. Defensoras e defensores dos direitos humanos foram mortos no Brasil, na Colômbia, no México, no Peru e na Venezuela. (...). Defensores dos direitos humanos e jornalistas também foram submetidos a ataques, ameaças, processos, detenções arbitrárias e vigilância ilegal na Bolívia, no Brasil, na Colômbia, em Cuba, no Equador, nos Estados Unidos, em El Salvador, na Guatemala, em Honduras, no México, na Nicarágua, no Peru e na Venezuela. (Anistia internacional, 2021, p.33)
\end{abstract}

Ainda no que se refere à periculosidade para os defensores dos direitos humanos no Brasil, em relatório produzido pela ONG Global Witness, o país foi identificado como o terceiro país mais letal para ativistas ambientais e de direitos humanos. Considerando que a questão territorial indígena atravessa os debates ambientais e de direitos humanos, é possível interpretar que tais dados versam também sobre o cenário de periculosidade no que se refere à defesa de direitos territoriais indígenas no país.

Segundo dados do CIMI (2019), foram registrados 113 assassinatos indígenas e 20 homicídios culposos indígenas. Somando estes dados aos dados de violências praticadas contra a pessoa indígena, foi registrado um total de 277 casos em 2019. Segundo o Atlas da 
Violência, divulgado pelo IPEA, as taxas de homicídios indígenas em municípios com TI's, no ano de 2019, se distribui da seguinte forma:

\begin{abstract}
sete estados tiveram taxas de homicídios indígenas maiores do que a taxa indígena nacional (20,4 por 100 mil habitantes): Mato Grosso do Sul $(53,6)$, Santa Catarina $(31,2)$, Amazonas $(30,2)$, Tocantins $(29,5)$, São Paulo $(24,9)$, Acre $(24,4)$ e Ceará $(20,42)$. Em alguns estados, as taxas de homicídios em municípios com terras indígenas são superiores às da taxa geral da UF: São Paulo $(24,9 ; 7,3)$, Mato Grosso do Sul $(53,6 ; 17,7)$, Santa Catarina $(31,2 ; 10,7)$ e Tocantins $(29,5 ; 29,0)$. Em termos absolutos, alguns desses estados tiveram números de homicídios inferiores: Ceará (3), Santa Catarina (4), Tocantins (4), Acre (5) e São Paulo (5). Enquanto outros apresentaram os maiores números: Amazonas (64) e Mato Grosso do Sul (41). (CERQUEIRA at al, 2021, p.86)
\end{abstract}

Ainda que o levantamento sobre as taxas de homicídios realizado pelo IPEA e pelo CIMI nos dê a dimensão da gravidade da situação, quando nos referimos a homicídios indígenas no Brasil, não é possível inferirmos as relações diretas com o agronegócio e seus ramos. Ainda assim, tais dados reafirmam a situação de emergência sobre a qual tais povos se encontram, no que se refere ao direito à vida e à defesa de seus territórios.

Destacamos aqui, por fim, também a situação de vulnerabilidade sobre a qual estes povos se encontraram, face ao avanço da pandemia do COVID-19. Um agravante da disseminação do vírus entre a população indígena, que possui relação direta com os setores do agronegócio, foram as cadeias de frigoríficos e abatedouros situadas próximas às Terras Indígenas. Muitos dos trabalhadores, hoje, nos frigoríficos, são indígenas, e em um contexto de epidemia, estes frigoríficos se tornaram centro de disseminação do vírus, sujeitando-os ao contágio e consequente disseminação do vírus nas comunidades.

Desta forma, buscamos sistematizar algumas das relações territoriais conflituosas que se estabelecem entre o agronegócio, seus agentes econômicos e representações políticas, e os povos indígenas no Brasil, na atualidade. No próximo item, apontaremos como estamos buscando entender estas relações no caso específico do Mato Grosso do Sul, em especial envolvendo os Guarani e Kaoiwá.

\title{
RELAÇÕES TERRITORIAIS ENTRE O AGRONEGÓCIO E OS GUARANI E KAIOWÁ NO MATO GROSSO DO SUL
}

Mato Grosso do Sul é um caso representativo no que se refere às relações territoriais conflituosas entre agronegócio e os povos indígenas. A expropriação de territórios dos povos originários no estado vem se dando a partir de alguns marcos históricos, em parte anteriores ao século XX. Barbosa e Mura (2011), por exemplo, destacam três grandes eventos históricos na região: a Guerra da Tríplice Aliança, a instalação da Companhia Matte Laranjeiras e a concessão de terras a produtores agrícolas e a instalação da Companhia Agrícola Nacional de Dourados (CAND). 
Ainda nas primeiras décadas do século XX, a maior presença dos não-indígenas na região teve como aliada a ação do Serviço de Proteção ao Índio (SPI) que, ao demarcar as Reservas Indígenas no estado, contribuiu para a "liberação para ocupação" de boa parte de seus territórios, e para sua remoção de seus territórios tradicionais. O órgão demarcou oito Reservas Indígenas entre 1915 a 1928, com área total de apenas 18.297 ha (Brand, 2004). Essa ação foi crucial para a abertura de áreas de produção no estado. Ao longo do século XX, muitas famílias foram sendo removidas de suas terras e transferidas para estas reservas. Apenas em fins de 1970, com a intensificação deste processo, se encorpa um conjunto de ações de resistência dos Guarani e Kaiowá e novos processos de regularização de Terras Indígenas.

O marco da década de 1970 é fundamental para entendermos os processos de espoliação territorial. De acordo com dados do IBGE, há o registro de produção de soja, aves e suínos em Mato Grosso do Sul desde o fim dos anos 70 (quando se iniciam as séries de dados municipais), de produção de cana-de-açúcar no início dos anos 80 e de produção de milho a partir do final dos anos 80. Segundo Brand (2004), foi neste período que se intensificaram as expulsões dos Guarani Kaiowá que "viviam em aldeias de fundo de pasto", ou seja, aldeias que permaneciam em áreas de mata que ainda restavam nas fazendas de gado extensivo que, com a necessidade de abertura de áreas para cultivo, foram desmatadas. Um dos resultados destas violências foi lento e sucessivo esparramo (Mota, 2017) ou sarambi (Chamorro, 2015), que consistiu no espalhamento das famílias antes articuladas em diversos tekoha.

É também a partir dos anos 1970 que acontece o fortalecimento das lutas territoriais indígenas de resistência, especialmente dos Guarani e Kaiowá, através das retomadas ou entradas (Thomaz de Almeida, 2000), que consistem em reocupar (e/ou permanecer em) territórios dos quais foram (ou estão sendo) expulsos, há mais ou menos tempo, incluindo áreas em disputa judicial. Estas ações passam a se articularem de diversas formas, com especial destaque para as Aty Guasu, que são as grandes assembleias, cerimonias religiosas e políticas que debatem as diversas questões e desafios enfrentados pelos Guarani e Kaiowá (Benites, 2012).

Neste ponto, reforçamos nossa perspectiva metodológica e epistemológica de buscarmos caminhos para, através de um esforço de diálogo de conceitos horizontais, tentarmos compreender os sentidos das ações territoriais. Eliel Benites nos apresenta a ideia de "levantar o tekoha" e sua profundidade. Para o autor,

Os tekohas se tornam vivos se existem pessoas viajando em dimensões espirituais e terrenas na busca do reconectar-se continuamente o teko com os Ñane Ramóĩ Jusu, no ensejo do teko araguyje. Viajar significa mover-se no tempo e nos diferentes patamares, realizando relações com os diversos Teko Jára e absorvendo múltiplos teko no encanto da trajetória da existência do ser guarani kaiowá. Levantar Tekoha, hoje, é retomar esta lógica da existência diante da transformação do pensar, do viver e de existir causada pela presença do modelo de ser não indígena. (2020, p. 37) 
As retomadas territoriais dos Guarani e Kaiowá representam, assim, caminhos para resgatar e manter o teko porã, a busca pelo jeito bom de se viver e o teko araguyje, o jeito sagrado de ser (Benites, 2020), o jeito baseado nas premissas religiosas e filosóficas dos Guarani e Kaiowá. As ações territoriais possuem, para este grupo étnico, segundo nos explica o autor, um componente de manter sua própria existência, não apenas no sentido de estarem vivos, mas de poderem estar no mundo de seu jeito. Já para o agronegócio, o sentido da ação territorial parece estar unicamente relacionado à defesa da propriedade privada e sua relevância econômica (Arruzzo, 2013).

Todos estes aspectos levaram à constituição de um sistema territorial (Raffestin, 1993) bastante conflituoso no estado de Mato Grosso do Sul já nas décadas de 80 e 90, o que se aprofundou bastante a partir dos anos 2000, com o crescimento expressivo do agronegócio no Brasil e no estado. A parti do século XXI, assiste-se a um intensivo crescimento, tanto na produção de grãos e carnes, quanto da cana-de-açúcar e usinas na região, como já apontamos em trabalhos anteriores (Arruzzo e Santos, 2021 e Arruzzo Cunha, 2019). São estes os setores que consideramos, no presente texto, como os principais representantes do agronegócio no estado, em especial na região cone-sul: a cadeia carne-grãos e o setor sucroenergético. Temos buscado identificar as especificidades das relações territoriais entre os diferentes ramos do agronegócio e os Guarani e Kaoiwá e identificado proximidades e distanciamentos entre suas formas e dinâmicas.

Embora o crescimento da produção de soja e milho tenha sido intensificado a partir de 2000, este se aprofunda ainda mais a partir de 2010 (dados de Produção Agrícola MunicipalIBGE). O mesmo, ainda segundo dados do IBGE, foi acompanhado por um aumento também da produção de aves e suínos (Cunha e Arruzzo, 2021), apontando para a importância da cadeia carne-grãos. O que aqui estamos denominando de cadeia carne-grãos, envolve as complexas articulações entre os circuitos espaciais de produção de soja e milho, seu beneficiamento em indústrias esmagadoras, sua transformação em ração, a destinação destas rações à criação de frangos e suínos em modernos espaços, integrados cada vez mais a grandes empresas de abate (muitas com atuação em escala mundial). Esta articulação entre os setores contribui para agregar valor aos produtos e, especialmente no caso da carne, para a redução dos custos de produção. No caso dos produtores de grãos, a presença de indústrias de beneficiamento e um mercado regional para a soja e o milho aumentam as possibilidades de comercialização da produção, que pode ter seu preço afetado por variações de câmbio.

No que se refere às ações territoriais, é importante ressaltarmos que as atividades relacionadas à produção de grãos acionam aspectos bastante exclusivistas da territorialidade (Sack, 1986), necessitando de grande controle do processo produtivo e, portanto, da terra. Estas atividades apresentam diferenças com relação às territorialidades estabelecidas pela criação de gado, por exemplo (Arruzzo, 2013). Segundo Chamorro, 
depois foram os peões nas novas propriedades, tornaram-se desnecessários e indesejados. Neste ambiente, foram saindo dos fundos das fazendas ou sendo levados pelos novos proprietários ou pelas entidades indigenistas para as reservas, que então, sim, começaram a crescer, em número de habitantes e problemas (2015, p. 23).

O crescimento da produção de cana-de-açúcar e seus derivados em Mato Grosso do Sul se desenvolve num ambiente econômico já voltado para o agronegócio, acirrando uma competição econômica com agentes dos setores de produção de grãos e de gado, por exemplo. É fundamental destacarmos alguns aspectos que são específicos desta atividade. Um ponto relevante para nossa análise é a distância da produção de cana-de-açúcar em relação à unidade processadora (usina), devido às restrições de estocagem da matéria-prima. Este aspecto da atividade pode alterar o mercado de terras e estimular relações conflituosas e competitivas com outras atividades produtivas. Castillo (2016) aponta um raio médio de alcance da produção de cana-de-açúcar de 40 a $50 \mathrm{~km}$ de distância da usina, podendo depender muito da qualidade das estradas e das diferentes situações regionais.

Como temos apontado, o avanço da cana-de-açúcar no estado se configura como um complicador a mais numa situação territorial já bastante complexa. No caso de Mato Grosso do Sul, considerando a necessária proximidade física e organizacional entre as áreas de produção de cana-de-açúcar e as unidades processadoras em áreas com produção já intensa de soja e milho, a instalação de uma usina próximo a uma área reivindicada pelos Guarani e Kaiowá é, necessariamente, um elemento que tende a adicionar tensão à questão.

Mapa 1- Terras Indígenas, violência contra o patrimônio indígena (de 2003 a 2019) e produção de soja por município (2019) 


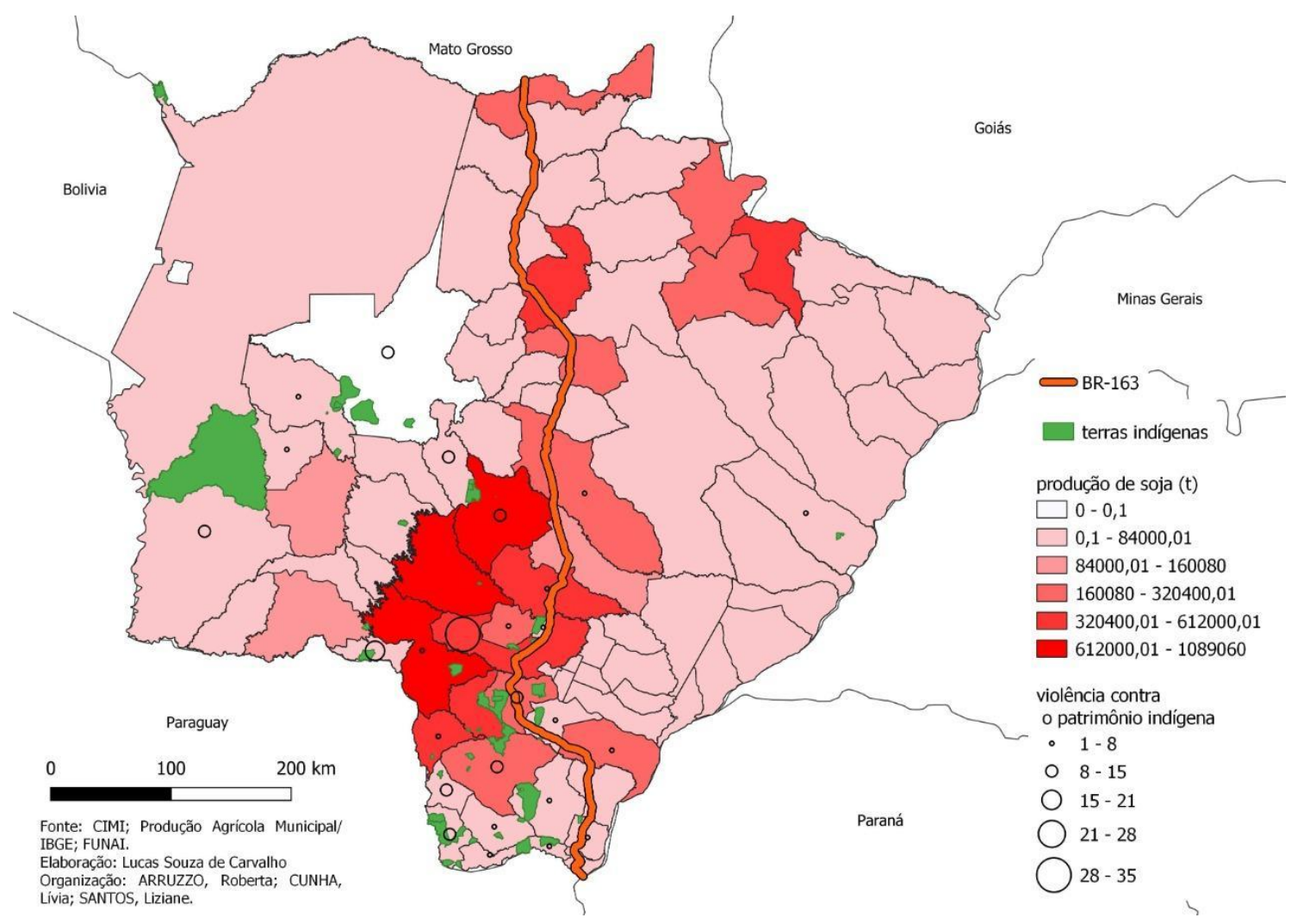

Fonte:

Mapa 2: Região produtiva de cana-de-açúcar, localização das usinas e das Terras Indígenas no cone-sul de Mato Grosso do Sul 


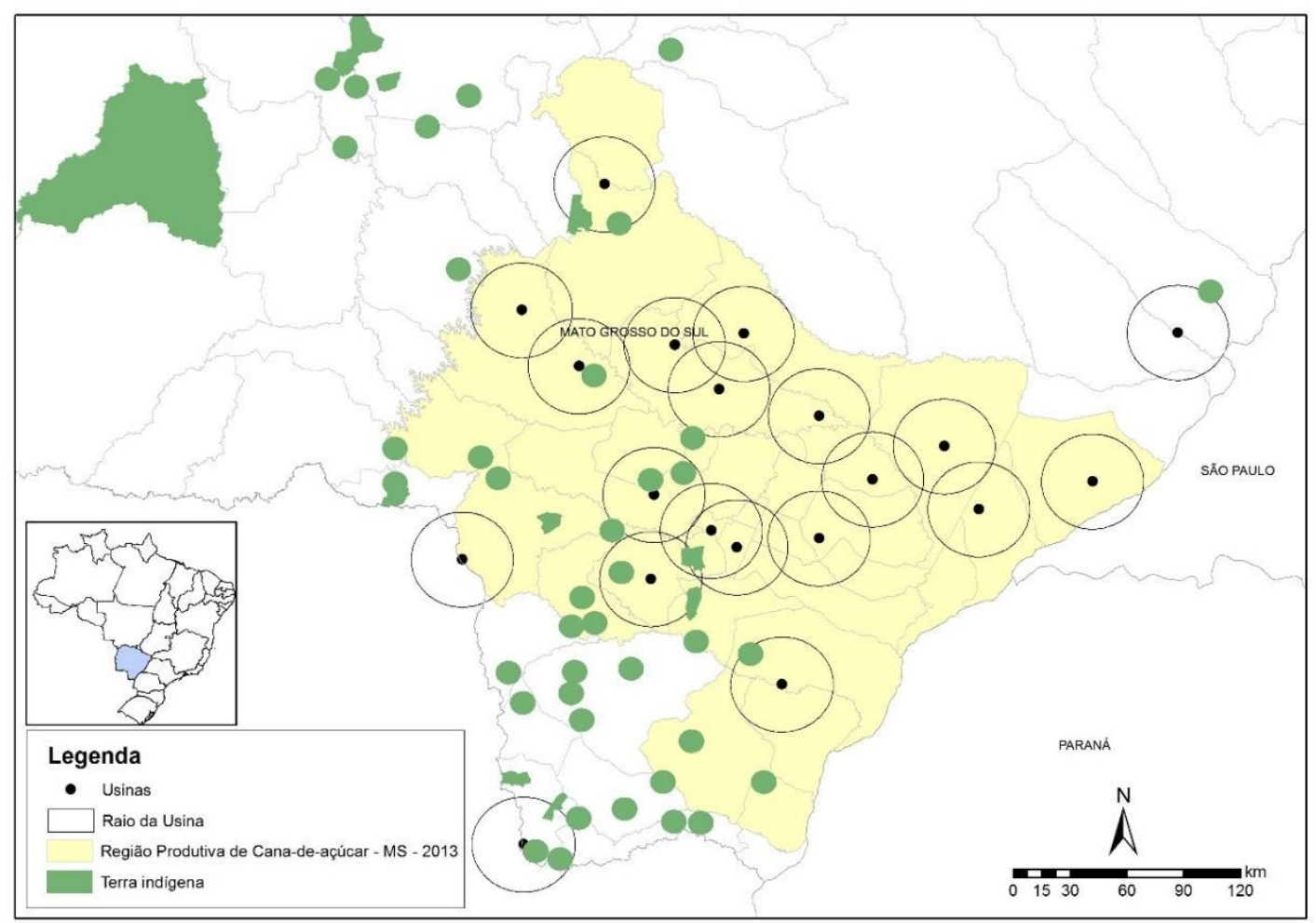

Fonte:

Os mapas 1 e 2, demonstram a grande coincidência espacial destas atividades produtivas e de uma grande quantidade de Terras Indígenas que, na região cone-sul do estado são, em grande parte, dos Guarani e Kaiowá. O mapa 1 indica ainda, com base nos Relatórios de Violências contra os Povos Indígenas elaborados pelo CIMI, uma grande coincidência destas áreas de produção com as violações contra o patrimônio indígena, que costuma coincidir com os processos que nomeamos de invasões territoriais na segunda parte deste texto. Este tipo de relação territorial conflituosa pode estar relacionada tanto à produção de soja como de cana-de-açúcar.

Como vimos, a presença de usinas nas proximidades de áreas reivindicadas pelos Guarani e Kaiowá aumenta a possibilidade de que haja produção de cana-de-açúcar dentro da área em disputa. Há diversos casos em que isso tem acontecido e ações regulares do Ministério Público Federal (MPF)3 buscando coibir esta prática, inclusive envolvendo grandes empresas transnacionais, como a Bunge e a Raízen4. A disputa por terras na proximidade da usina, inclusive com a produção de grãos, buscando garantia do seu abastecimento de matéria-prima, parece ser um elemento que estimula a prática do arrendamento e que movimenta o mercado de terras.

No caso do setor sucroenergético, devido à necessidade de proximidade do mercado consumidor, as ações do MPF têm sido mais efetivas na coibição da compra de matéria-prima produzida em áreas reivindicadas pelos Guarani e Kaoiwá. Por outro lado, a dinâmica de 
produção e comercialização de grãos de diversas formas, podendo ser destinados facilmente ao mercado interno ou externo, torna esse tipo de ação de controle bastante difícil no caso da cadeia carne-grãos. Desta forma, as especificidades dos processos produtivos e logísticos da soja e do milho tornam o controle sobre a sua origem e destino bastante complexos. Devido a isso, muitos fazendeiros que produzem dentro de Terras Indígenas, conseguem seguir comercializando a produção, mesmo durante diferentes fases da regularização fundiária.

Por outro lado, as ações de resistência também são adaptadas e realizadas em outras escalas e por outros agentes. Em 2015 uma campanha internacional solicitava o boicote aos produtos do agronegócio de Mato Grosso do Sul. Os cartazes, reproduzidos em diversas línguas, indicavam que os produtos como carne, soja, açúcar e biodiesel continham sangue indígena. A campanha foi lançada em plena Assembleia Legislativa do estado pela então representante da APIB, Sônia Guajajara, e causou intensa repercussão. Os Guarani e Kaiowá têm, assim, desenvolvido diversas articulações políticas que ultrapassam, em muito, os não demarcados limites de seus tekoha. Ládio Veron ${ }^{6}$, em viagem pela Europa, em 2017, apontava seus objetivos:

\begin{abstract}
Nós viemos aqui para pedir-lhe para formar um grupo que visite a nossa terra, de forma que o olho da Europa esteja conosco e veja de perto todos os produtos que são produzidos no Mato Grosso do Sul, produtos geneticamente modificados e que para tanto utilizam produtos químicos, que depois são trazidos para vocês. Isso acontece na terra dos Guarani-Kaiowá. Na Europa, queremos formar uma rede de apoio que esteja ligada diretamente aos acampamentos indígenas. Será necessário instalar nas terras novamente ocupadas uma rádio via internet, porque agora durante as retomadas [as novas ocupações] não temos rede de celular ou internet, nem eletricidade para carregá-los, e quando somos atacados muitas vezes ninguém fica sabendo. Nós também queremos criar uma escola de formação política para que não só os líderes, mas também os jovens possam conhecer os seus direitos e saber qual caminho tomar, junto com seus irmãos da Europa (Veron, 2017).
\end{abstract}

No que se refere aos conflitos ambientais, como aponta também Ládio Veron, em ambos os setores ocorrem intensas aplicações de agrotóxicos, poluindo rios, terras e o ar no entorno muito próximo às aldeias. Diversas tem sido as denúncias do Guarani e Kaiowá da aplicação de agrotóxicos diretamente em cima das aldeias, via avião, causando muitos danos ambientais e afetando gravemente a saúde. Ambas atividades também são apontadas como responsáveis pela intensificação do desmatamento na região (Chamorro, 2015; Brand, 2004).

Assim como as questões ambientais, no que se refere às violências físicas, vemos uma grande presença de assassinatos e tentativas de assassinato no estado a partir dos anos 2000, sem conseguirmos diferenciar as possibilidades de correlação com os setores produtivos nos dados que dispomos. Os dados dos Relatórios de Violências contra os Povos Indígenas do CIMI apontam que, entre 2003 e 2009, um total de 445 indígenas foram assassinados no estado. Este número representa 39, 4\% dos assassinatos de indígenas registrados no Brasil inteiro (Santos, Amado e Pasca, 2021). Este número começa a crescer em 2005 e encontra seu triste ápice nos anos 2007 e 2008, quando 94 indígenas foram assassinados no estado. Por outro lado, no caso do setor sucroenergético, podemos somar um aspecto trabalhista que parece poder ser enquadrado nesta categoria. Muitas têm sido as denúncias trabalhistas, violências diversas e até mesmo assassinatos, relacionados ao grande número de trabalhadores 
indígenas que se envolvia, pelo menos até 2017, nas atividades do corte da cana-de-açúcar (Cunha, 2017).

Por fim, apontamos o aspecto da morosidade do processo de regularização das Terras Indígenas de Mato Grosso do Sul. Segundo os dados da Funai de 2020, das 63 Terras Indígenas do estado, apenas 29 estão completamente regularizadas e 15 ainda estão na primeira fase do processo. Somado a isso,

Das 32 terras dos Guarani Kaiowá e Ñhandeva no estado, as comunidades estão atualmente na posse efetiva de apenas $29 \%$ da área total delimitada, o que significa uma posse de apenas 1,1 ha por pessoa. (Santos, Amado e Pasca, 2021, p. 1)

Em parte estes dados se devem à forte judicialização do processo demarcatório, que já apontamos anteriormente. Ainda segundo os autores do relatório:

\begin{abstract}
É importante destacar que mesmo as terras indígenas homologadas estão sendo questionadas por via judicial, como por exemplo a TI Limão Verde, TI Ñande Ru Marangatu e TI Arroio Korá. Isto evidencia a pressão dos atores econômicos do estado, não somente para barrar os processos de regularização em curso, mas também para impedir a posse dos indígenas das terras já delimitadas. (Santos, Amado e Pasca, 2021, p. 8)
\end{abstract}

Toda esta morosidade e judicialização no processo demarcatório tem contribuído para o acirramento do conflito territorial entre povos indígenas e agronegócio no estado. Um de seus principais movimentos políticos para buscar solucionar suas questões territoriais tem sido os processos políticos de retomada de terras. Estas entradas ou retomadas, que já citamos anteriormente, estão longe de ser restritas aos Guarani e Kaiowá. Há, na atualidade, diversos acampamentos de retomadas indígenas no estado, muitos também vinculados ao movimento territorial dos Terena (Amado, 2019). Dados recentes apontam a presença de 22 acampamentos de retomadas Guarani e Kaiowá e 30 dos Terena (Santos, Amado e Pasca, 2021). É através das retomadas que os Guarani e Kaoiwá, bem como outros povos indígenas do Brasil, têm buscado resistir e insurgir contra o forte controle territorial do agronegócio em diversos espaços brasileiros.

\title{
CONSIDERAÇÕES FINAIS
}

Buscamos, no presente artigo, abordar as relações, em grande parte de cunho conflituoso, que se estabelecem entre o agronegócio e os povos indígenas no Brasil. Temos tentado entender estas relações pela perspectiva territorial, através das ações necessárias para se estabelecer e criar territórios. Diferentes agentes praticam estas ações, com grande dissimetria de poder e sentidos muito diversos. Buscamos destacar, ao longo do texto, tanto numa escala mais nacional quanto na escala mais local dos Guarani e Kaiowá, as relações de poder e as resistências.

As ações de povos como os Guarani e Kaiowá, além de resistir às forçosas tentativas de homogeneização da vida ambiental, econômica e social, apresentam também caminhos diferentes, insurgentes. Por fim, retomando nossos diálogos com o geógrafo kaiowá Eliel 
Benites, o autor tem apontado em suas falas que as retomadas contribuem para adiar o Ara Paha. Muito simplificadamente, o Ara Paha seria uma espécie de fim dos tempos para os Guarani e Kaiowá, sem que signifique, necessariamente sua morte física. Este fim dos tempos seria os Guarani e Kaiowa deixarem de buscar o Teko Araguyje, o jeito sagrado de ser, e passarem a viver como os karai (não-indígenas). Desta forma, em diálogo com Ailton Krenak, as retomadas contribuem para adiar o fim do mundo.

\section{AGRADECIMENTOS}

Agradecemos aos Guarani e Kaiowá pelas diversas acolhidas, encontros e trocas em que aprendemos tanto. Agradecemos também ao CNPq, a CAPES e a UFRRJ pelas bolsas de iniciação científica, mestrado e doutorado envolvidas nestes 10 anos de pesquisas sobre os Guarani e Kaiowá. Ao CNPQ também agradecemos o financiamento de um projeto de pesquisas que permitiu nossa primeira ida coletiva a campo, em 2015 e pelo financiamento dos projetos coordenados por Júlia Adão Bernardes, que sempre nos inclui. Por fim, agradecemos, em memória, a Rubem Thomaz de Almeida, por tudo. Rubinho, aguyjevete.

\section{NOTAS}

“Art. 231. São reconhecidos aos índios sua organização social, costumes, línguas, crenças e tradições, e os direitos originários sobre as terras que tradicionalmente ocupam, competindo à União demarcá-las, proteger e fazer respeitar todos os seus bens.” (BRASIL, Constituição Federal de 1988).

2 "Art. 232. Os índios, suas comunidades e organizações são partes legítimas para ingressar em juízo em defesa de seus direitos e interesses, intervindo o Ministério Público em todos os atos do processo." (BRASIL, Constituição Federal de 1988).

3 Ver "MPF/MS questiona BNDES por financiar usinas que compram cana cultivada em áreas indígenas" disponível em: http://mpf.jusbrasil.com.br/noticias/2182161/mpf-ms-questiona-bndes-por-financiar-usinas-que-compram-cana-cultivada-emareas-indigenas.

4 Ver "MPF/MS pede indenização de R\$ 170 milhões para comunidade indígena Guyraroká" disponível em: http://www.prms.mpf.mp.br/servicos/sala-de-imprensa/noticias/2012/06/mpf-ms-pede-indenizacao-de-r-170-milhoes-para-co munidade-indigena-guyraroka.

5 Filho do cacique Marcos Veron, assassinado a mando de fazendeiros em 2003.

\section{REFERÊNCIAS}

ALFINITO, Ana Carolina Alfinito; AMADO, Luiz Henrique Eloy. A aplicação do marco temporal pelo poder judiciário e seus impactos sobre os direitos territoriais do povo terena. In: ALCÂNTARA, Gustavo Kenner; TINÔCO, Lívia Nascimento; MAIA, Luciano Mariz. Índios Direitos Originários e Territorialidade. Brasília: ANPR, 2018. 227-264. 
ALTIERI, Miguel A.; NICHOLLS, Clara Inés. Do modelo agroquímico à agroecologia: a busca por sistemas alimentares saudáveis e resilientes em tempos de COVID-19. Desenvolvimento e Meio Ambiente, v. 57, 2021.

AMADO, Luiz Henrique Eloy. Vukápanavo o despertar do povo Terena para os seus direitos: movimento indígena e confronto político. Rio de Janeiro: Museu Nacional (Tese de Doutorado). 2019.

AMADO, Luiz, Henrique Eloy; VIEIRA, Victor Hugo Streit. O tratamento jurídico-penal reservado aos indígenas sob a ótica intercultural e decoloniail, 2020.

ANISTIA INTERNACIONAL. Relatório sobre criminalização e assédio de lideranças indígenas no Brasil. Indigenous Peoples Rights International, 2021.

APIB. Dossiê internacional de denúncias dos povos indígenas do Brasil. Brasília: Articulação dos Povos Indígenas do Brasil (APIB), 2021.

APIB. Relatório Covid-19 e Povos indígenas: O enfrentamento das violências durante a pandemia. Brasília: Comitê Nacional pela Vida e Memória Indígena, 2020(a).

APIB. V. III: Dossiê Como as Corporações Globais contribuem para violações de direitos dos povos indígenas da Amazônia Brasileira. Brasília: Articulação dos Povos Indígenas do Brasil (APIB), 2020 (b).

ARRUZZO, Roberta Carvalho. Construindo e desfazendo territórios: As relações territoriais entre os Paresi e os não-índios na segunda metade do século XX. Rio de Janeiro: Tese de doutorado (Doutorado em Geografia)-Instituto de Geociências, Universidade Federal do Rio de Janeiro, 2009.

ARRUZZO, Roberta Carvalho. Os sentidos das territorialidades e os conflitos territoriais entre agronegócio e os Guarani Kaiowá no Mato Grosso do Sul. In: Encontro de Geografos da América Latina, 2013, Lima. p. 1-20.

ARRUZZO, Roberta Carvalho; CUNHA, Lívia Domiciano. O setor sucroenergético em Mato Grosso do Sul: aspectos econômicos, vulnerabilidades e conflitos territoriais. In: BERNARDES, Julia Adão; CASTILLO, Ricardo. Espaço geográfico e competitividade: regionalização do setor sucroenergético no Brasil. Lamparia: Rio de Janeiro, ed, 2019.

ARRUZZO, Roberta Carvalho; SANTOS, Liziane Neves. Conflitos, violências e resistências: o movimento de recuperação territorial dos guarani e kaiowá e a cadeia carne grãos em Mato Grosso do Sul. In: BERNARDES, Julia Adão (Org.). O setor carne-gãos no Centro Oeste: circuitos produtivos, dinâmicas territoriais e contradições. Lamparina: Rio de Janeiro, 2021.

BARBOSA, Pablo A; MURA, Fabio. Construindo e reconstruindo territórios Guarani: dinâmica territorial na fronteira entre Brasil e Paraguai (séc. XIX-XX). Journal de La societé dês américanistes. Tome 97, $\mathrm{n}$ 2, 2011. Acesso em:< https://journals.openedition.org/jsa/11963?lang=en> 
BENITES, Eliel. Tekoha Ñeuropu'ã: Aldeia que se levanta/Tekoha Neropu'ã: indian village that gets up. Revista Nera, n. 52, 2020. 19-38.

BENITES, Tonico. Trajetória de luta árdua da articulação das lideranças Guarani e Kaiowá para recuperar os seus territórios tradicionais tekoha guasu. RAU-Revista de Antropologia da UFSCAR, São Carlos, v. 4, n. 02, 2012. 165-174.

- Recuperação dos territórios tradicionais Guarani-Kaiowá. Crónica de táticas e estratégias. Journal de la Société des Américanistes, 2014. 229-240. Acesso em: https://journals.openedition.org/jsa/14022.

BRAND, Antonio. Os complexos caminhos da luta pela terra entre os Kaiowá e Guarani no MS. Tellus, p. 137-150, 2004.

CASTILLO, Ricardo Abid. Dinâmicas recentes do setor sucroenergético no Brasil: competitividade regional para o bioma Cerrado. GEOgraphia, v. 17, n. 35, 2016. 95-119.

CASTILHO, Alceu Luís. Partido da terra. Editora Contexto, 2012.

CERQUEIRA, Daniel. Atlas da Violência 2021 - IPEA. São Paulo: FBSP, 2021.

CHAMORRO, Graciela. História Kaiowa. Ed: Nhanduti Editora, 2015.

CIMI. Relatório Violência Contra os Povos Indígenas no Brasil. Conselho Indigenista Missionário (Cimi), 2019.

CUNHA, Lívia Domiciano. O avanço da fronteira agrícola no Mato Grosso do Sul e a precarização das práticas espaciais Guarani e Kaiowa. Niterói, 2017. 133 f. Dissertação (Mestrado em Geografia) - Universidade Federal Fluminense, 2017.

CUNHA, Livia Domiciano; ARRUZZO, Roberta Carvalho. O circuito espacial da produção de carne-grãos em Mato Grosso do Sul: espacializações e agentes principais. In:BERNARDES, Julia Adão (Org.). O setor carne-gãos no Centro Oeste: circuitos produtivos, dinâmicas territoriais e contradições. Lamparina: Rio de Janeiro, 2021.

ELIAS, Denise. Agronegócio e novas regionalizações no Brasil. Revista Brasileira de Estudos Urbanos e Regionais, v. 13, n. 2, p. 153-153, 2011.

FREDERICO, Samuel. Economia política do território e as forças de dispersão e concentração no agronegócio brasileiro. GEOgraphia, v. 17, n. 35, p. 68-94, 2015.

GURGEL, Aline do Monte; SANTOS, Mariana Olívia Santana; GURGEL, Idê Gomes Dantas. Saúde do campo e agrotóxicos: vulnerabilidades socioambientais, político-institucionais e teórico-metodológicas / organizadores. Recife, Ed. UFPE, 2019.

LEITE, Sergio Pereira. Dinâmicas de terras, expansão do agronegócio e financeirização da agricultura: por uma sociologia das transformações agrárias. Revista Latinoamericana de Estudios Rurales, v. 4, n. 7, 2019. 
MOTA, Juliana Grasiéli Bueno. Os Guarani e Kaiowá e suas lutas pelo tekoha: os acampamentos de retomadas e a conquista do teko porã (bem viver). Revista Nera, n. 39, p. 60-85, 2017.

PORTO-GONÇALVES, C. W. Dos cerrados e suas riquezas. Publicado em 17 de setembro de 2008 e disponível em: http://www.povosdocerrado.org.br/?p=12.

RAFFESTIN, C. Por uma geografia do poder. Ática: São Paulo, 1993. 269 p.

RIBEIRO, A. C. T. Territórios da sociedade: por uma cartografia da ação. In: SILVA, C. A. (org). Território e ação social: sentidos da apropriação urbana. Rio de Janeiro: Lamparina, 2001 .

SACK, R. Human territoriality, its theory and history. Cambridge: University Press, 1986.

SANTOS, Anderson de Souza; AMADO, Luiz Henrique Eloy; PASCA, Dan. "É muita terra pra pouco índio"? Ou muita terra na mão de poucos? Conflitos fundiários no Mato Grosso do Sul. Instituto Socioambiental (ISA), Relatório, 2021. Disponível em: https://acervo.socioambiental.org/acervo/documentos/e-muita-terra-pra-pouco-indio-ou-muita -terra-na-mao-de-poucos-conflitos

SANTOS, M. Por uma geografia cidadã: por uma epistemologia da existência. Boletim Gaúcho de Geografia, Porto Alegre, nº 21, 1996. 7-192

SANTOS, M. A Natureza do Espaço: técnica e tempo, razão e emoção. São Paulo: Edusp, 1999.

SOUZA SANTOS, Boaventura de. Para uma sociologia das ausências e uma sociologia das emergências. In: Conhecimento prudente para uma vida decente. São Paulo: Ed. Cortez, 2006.

THOMAZ DE ALMEIDA, Rubem F. A “Entrada" no tekoha. In: Povos Indígenas no Brasil: 196-2000, Editor C.A. Ricardo, ISA, São Paulo, 745-748, 2000.

VERON, Ládio. O Grito pela terra: entrevista com Ládio Veron, publicada em 22 de junho de 2017.

Disponível

em:

http://www.ihu.unisinos.br/78-noticias/568930-o-grito-pela-terra-entrevista-com-ladio-veron.

Acessado em dezembro de 2020.

\section{COMO CITAR ESTE TRABALHO}

ARRUZZO, Roberta Carvalho. CUNHA, Livia Domiciano. SANTOS, Liziane Neves dos. Relações territoriais entre povos indígenas e agronegócio no Brasil: conflitos e resistências.

Revista Tamoios, São Gonçalo, v. 18, n. 1, p. 165-185, 2022. Disponível em: https://doi.org/10.12957/tamoios.2022.63879. Acesso em: DD MMM. AAAA. 